\title{
RENDIMENTO E COMPOSIÇÃO FÍSICO-QUÍMICA DO QUEIJO PRATO ELABORADO COM LEITE PASTEURIZADO PELO SISTEMA HTST E INJEÇÃO DIRETA DE VAPOR ${ }^{1}$
}

\author{
PATRICIA RODRIGUES DA SILVEIRA ${ }^{2}$ \\ LUIZ RONALDO DE ABREU ${ }^{3}$
}

\begin{abstract}
RESUMO - Avaliaram-se o rendimento, a transição de gordura e extrato seco do leite para a coalhada e as características físico-químicas do queijo prato produzido com leite pasteurizado pelo sistema de placas (ou HTST) e injeção direta de vapor (IDV). Utilizou-se o delineamento inteiramente casualizado, constituído por dois tratamentos (HTST e IDV) e seis repetições (fabricações). O sistema IDV incorporou cerca de 8,5\% de água ao leite, havendo como consequiência redução $(\mathrm{P}<0,05)$ no teor de sólidos totais, na gordura e na acidez do leite pasteurizado. Observou-se maior transição de gordura do leite para a coalhada, quando esse foi
\end{abstract}

TERMOS PARA INDEXAÇÃO: Acidez, crioscopia, extrato seco, fosfatase, gordura, peroxidase, sistema de pasteurização.

\section{YIELD AND PHYSICAL-CHEMISTRY COMPOSITION OF PRATO CHEESE ELABORATED WITH MILK PASTEURIZED BY THE HTST AND DIRECT STEAM INJECTION}

\begin{abstract}
Cheese yield, fat and dry matter transitions from milk pasteurized by the two pasteurization systems to the curd, as well as, the physical-chemistry characteristics of cheeses were evaluated. The statistical treatment was full randomly, with two treatments: pasteurization by high temperature short time system (HTST) and direct steam injection (DSI), with six replications. The DSI system incorporated about $8,5 \%$ of water to the milk, having as consequence reduction $(\mathrm{P}<.05)$ in the total solids, in the fat and in the acidity of the pasteurized milk. Larger transition of fat of the milk to the curd was observed,
\end{abstract}

submetido ao sistema de pasteurização por IDV, o que resultou em maior rendimento dos queijos fabricados com leite pasteurizado por esse sistema $(8,48$ litros de leite/kg de queijo), quando comparado ao sistema HTST (9,54 litros de leite/kg de queijo). Os queijos fabricados com o sistema IDV apresentaram teores mais elevados de gordura e gordura no extrato seco (GES) (29,06 e 55,25\%), quando comparados aos do sistema HTST (27,02 e 49,88\%), respectivamente. Conclui-se que o sistema IDV proporciona aumentos expressivos no rendimento de queijos e que, entre os constituintes do leite, a gordura foi a principal responsável por este aumento.

INDEX TERMS: Acidity, crioscopy dry extract, phosphatase, fat, peroxidase, pasteurization system.

1. Parte da dissertação de Mestrado do primeiro autor, financiada pela FAPEMIG/FIEMG.

2. Zootecnista, estudante de Doutorado da UNIVERSIDADE FEDERAL DE LAVRAS/UFLA - Caixa Postal 37 37200-000 - Lavras, MG. provolon@ufla.br

3. Professor Titular do Departamento de Ciência dos Alimentos/UFLA, bolsista do CNPq. labreu@ufla.br 


\section{INTRODUÇÃO}

A indústria queijeira do Brasil está conseguindo elaborar produtos que vêm atingindo, gradativamente, melhor aceitação no mercado. Com o passar dos anos, novas tecnologias surgiram, inovando a indústria laticinista. A maneira pela qual os antigos fabricavam queijos, como forma de preservação do leite, ou para pequenas comercializações, foi marcante na economia do setor. Entretanto, novos investimentos tecnológicos e financeiros foram necessários para acompanhar o avanço da sociedade como um todo. Entre os produtos de laticínios, o queijo é um dos mais difundidos.

Entre os diversos tipos de queijos fabricados no Brasil, o prato destaca-se como um dos mais importantes. Ele foi introduzido no Brasil por imigrantes dinamarqueses, e originou-se dos queijos tybo e danbo, dinamarqueses, e do gouda, holandês. Possui grande importância no meio comercial, ocupando o segundo lugar em produção no Brasil. Esse tipo de queijo caracteriza-se por ter sabor suave, consistência macia, fácil fatiabilidade e melhor padronização tecnológica, sendo, portanto, mais bem caracterizado comercialmente.

$\mathrm{Na}$ elaboração do queijo prato, a operação de pasteurização é uma exigência legal, trazendo, além da segurança sanitária, padronização tecnológica, uniformização do sabor e redução da incidência de defeitos e perdas, em conseqüência das fermentações anormais, sendo considerado, portanto, um dos fatores indispensáveis para a qualidade do produto oferecido ao mercado. O leite é um produto altamente perecível e a pasteurização é a forma de prolongar o seu tempo de conservação, preservando suas características naturais, além de torná-lo seguro sob o ponto de vista de saúde pública. A pasteurização consiste no emprego de calor, com o objetivo de eliminar totalmente a flora microbiana patogênica, a maioria fermentativa, sem alteração sensível de sua constituição física e do equilíbrio químico do leite, sem prejudicar seus elementos bioquímicos, como também suas propriedades organolépticas (BRASIL, 1980).

No Brasil, a legislação vigente (BRASIL, 1980) permite dois processos de pasteurização: a) pasteurização lenta, que consiste no aquecimento do leite a 62$65^{\circ} \mathrm{C}$ por 30 minutos, mantendo-se o leite em grande volume sob agitação mecânica lenta; b) pasteurização de curta duração, que consiste no aquecimento do leite em camada laminar a $72-75^{\circ} \mathrm{C}$ por 15 a 20 segundos, em aparelhagem própria.
A legislação em vigor não diferencia o tratamento térmico da pasteurização para o leite de consumo daquele destinado à elaboração de queijos, tanto em relação à temperatura como ao tempo de residência. Entretanto, alguns autores (FURTADO, 1973; SOUZA, 1960) recomendam temperaturas não superiores a $72^{\circ} \mathrm{C}$ para leite destinado à fabricação de queijos.

A eficiência da pasteurização é definida pelos testes de fosfatase alcalina e peroxidase, contagem de microrganismo aeróbios mesófilos e quantificação de microrganismos do grupo dos coliformes totais e fecais. A prova de fosfatase deve ser negativa e da peroxidase, positiva; o número de colônias de microorganismos aeróbios estritos e facultativos mesófilos por $\mathrm{ml}$ para o leite tipo C não deve ultrapassar a 150.000 após pasteurização e, finalmente, deve ser constatada a ausência de coliformes em 1ml (BRASIL, 1980).

O sistema IDV é considerado pelo Ministério da Agricultura como um sistema de termização, podendo ser aplicado em uma indústria de laticínios que recebe até 5.000 litros de leite.

O tratamento térmico feito pelo sistema IDV, através de bicos com difusor e abafador em aço inoxidável, utilizando-se vapor purgado e duplamente filtrado, é importante para a fabricação de queijos, principalmente queijos especiais, porque acentua as características sensoriais de cada tipo de queijo.

O sistema de injeção direta de vapor aliado às boas práticas de fabricação é responsável pela garantia da excelente qualidade de queijos finos produzidos nessa indústria. Com isso, na nova indústria Serrabella, provida de estruturas e equipamentos modernizados e dentro dos padrões exigidos pelo Ministério da Agricultura, foi adotado o sistema de injeção direta de vapor para o tratamento térmico do leite. Conseqüentemente, houve a necessidade de maiores investimentos para a melhoria do sistema, preservando os mesmos princípios, já que esse vem atingindo ótimos resultados, garantindo a qualidade e principalmente a segurança dos produtos elaborados.

O processo de pasteurização pode ser realizado por meio de vários processos, os quais utilizam diferentes equipamentos e têm como objetivos a eliminação total dos microorganismos patogênicos e a redução do número de microorganismos indesejáveis ao processo de fabricação. No caso particular do Brasil, além do sistema de pasteurização em placas ou HTST (hight temperature short time), outros sistemas tradicionais, como ejetor de vapor, injeção direta de vapor e camisa de vapor, continuam sendo utilizados, embora haja tendência 
de serem legalmente proibidos. A substituição desses sistemas descontínuos de pasteurização do leite destinado à fabricação de queijos pelo contínuo (sistema de placas), nas pequenas indústrias de laticínios, está se tornando prática bastante comum, principalmente em função da grande oferta de sistemas contínuos, o que está levando à diminuição considerável de seus preços. Entretanto, observações práticas têm demonstrado que queijos prato e afins, fabricados com leites pasteurizados pelos sistemas de placas e injeção direta de vapor, apresentam diferenças sensíveis em suas características sensoriais, bem como nos índices de maturação e no rendimento.

O sistema de pasteurização HTST ou sistema de placas corresponde ao aquecimento e resfriamento indireto, ou seja, o leite não entra em contato direto com o fluido aquecedor, pois existe uma parede metálica que os separa. Geralmente, a maioria dos aquecedores em laticínios utiliza o sistema indireto. Esse princípio é empregado principalmente nos pasteurizadores de placas e tubulares em fluxo contínuo e tanques de pasteurização lenta em fluxo descontínuo. No sistema de placas, a pasteurização é realizada pelo aquecimento rigorosamente uniforme do leite à temperatura de $\pm 75^{\circ} \mathrm{C}$ durante \pm 15 segundos, tempo denominado de retenção (VENTURA e RUSIG, 1983). Uma vantagem do sistema HTST em relação ao sistema de injeção direta de vapor é que ele permite o emprego do leite pasteurizado em vários produtos de laticínios.

O sistema de injeção direta de vapor emprega, por meio de um cano inoxidável, o contato direto do vapor de água com o leite. $\mathrm{O}$ emprego de vapor direto no leite ficou conhecido como procedimento de Heryng (FLEISCHMANN, 1924), o qual colocava o vapor em forma de névoa no leite, mediante um pulverizador de vapor, aquecendo o leite entre $75-80^{\circ} \mathrm{C}$. Observava-se, após o resfriamento da mistura, aumento de 10 a $15 \%$ no peso inicial do leite. Esse processo trazia várias vantagens, entre elas a destruição completa dos microrganismos patógenos.

Ventura et al. (1984) observaram que o queijo tipo prato fabricado com leite pasteurizado por ejetor de vapor possui aumento no rendimento, sem variação na sua composição. Esse aumento seria devido ao maior aproveitamento de todos os constituintes do leite. $\mathrm{O}$ processo reduz o tamanho dos glóbulos de gordura, fazendo com que ocorra maior retenção dos mesmos na coalhada. Permite também a retenção das soroproteínas desnaturadas e complexadas com as caseínas, o que leva a modificações na massa do queijo, melhorando o sabor, aroma e textura. De acordo com Ventura (1981), a incorporação de água pode variar de 7 a $11 \%$, em função da pressão de vapor e da temperatura inicial do leite cru, quando se utiliza o sistema ejetor de vapor, que é bastante similar ao sistema de injeção direta de vapor.

$\mathrm{Na}$ indústria queijeira, as principais preocupações são a qualidade e o rendimento, tendo em vista a maximização de seus lucros. Portanto, a composição do leite destinado à produção de queijo é muito importante (MARZIALI e NG-KWA-HANG, 1986). A composição físico-química do leite sofre uma série de alterações quando esse é submetido a tratamento térmico. O grau de alteração depende da temperatura e do tempo de aplicação (SILVA, 1975). A maior parte de gordura e proteínas, $30 \%-50 \%$ dos minerais, algumas proteínas do soro e parte da lactose, no processo de elaboração de queijos, contribuem para a formação do extrato seco do queijo, afetando diretamente a sua composição. Assim, o tipo de tratamento térmico a que é submetido o leite destinado à fabricação de queijos é essencial na qualidade final do produto, já que pode promover mudanças nos seus vários constituintes (SAN JOSÉ, 1979; HASHZUME e SATO, 1988), principalmente nas diferentes frações protéicas e, conseqüentemente, na distribuição de nitrogênio (WOLFSCHOON-POMBO, 1983).

Diferenças de rendimento observadas em queijos fabricados com leite pasteurizado por diferentes sistemas são de grande interesse prático e econômico para a indústria de laticínios. Os principais fatores que influenciam no rendimento dos queijos são: a composição do leite, principalmente a quantidade de gordura e caseína, a porcentagem de transição dos constituintes do leite para queijo e a quantidade de umidade retida no queijo, além da incorporação de sais insolúveis e concentração de sal $(\mathrm{NaCl})$ adicionado à massa (SEAB, 1992). Além desses fatores, de acordo com Folegatti (1994), os tratamentos térmicos e mecânicos aplicados ao leite e ao coágulo durante o processamento influenciam de modo sensível no rendimento.

A indústria de laticínios não possui ainda informações precisas e tecnicamente embasadas a respeito de qual sistema de pasteurização, IDV OU HTST, é o mais adequado para se obter queijos de qualidade desejada. Portanto, objetivou-se comparar os processos de pasteurização em placas e injeção direta de vapor do leite destinado à fabricação do queijo prato, visando a verificar as diferenças quanto ao rendimento e às características físico-químicas dos queijos fabricados com leite pasteurizado pelos dois sistemas.

Ciênc. agrotec., Lavras. V.27, n.6, p.1340-1347, nov./dez., 2003 


\section{MATERIAL E MÉTODOS}

O experimento foi desenvolvido nas instalações do Centro de Excelência em Laticínios (CEL) e no Laboratório de Laticínios do Departamento de Ciência dos Alimentos da Universidade Federal de Lavras (UFLA), ambos localizados na cidade de Lavras, Minas Gerais.

$\mathrm{O}$ leite de plataforma (tipo C), padronizado a $3,5 \%$ de gordura e proveniente de um mesmo tanque, foi dividido em duas partes, após retiradas amostras para análises. A primeira foi destinada à pasteurização pelo sistema de injeção direta de vapor e a segunda, pelo sistema HTST (High Temperature Short Time) ou sistema de placas. No sistema HTST, o leite foi aquecido a $72^{\circ} \mathrm{C}$, por quinze segundos, enquanto no sistema injeção direta de vapor utilizou-se o binômio tempo/temperatura de $70^{\circ} \mathrm{C} / 5 \mathrm{~min}$. Em ambos processos foi utilizado o resfriador de placas para o resfriamento do leite. $\mathrm{O}$ delineamento experimental utilizado foi o inteiramente casualizado, constituído de dois tratamentos (HTST e injeção direta de vapor), com seis repetições (fabricações). Cada fabricação foi conduzida com 100 litros de leite pasteurizado, inoculado com $1,5 \%$ de fermento lático mesofílico tipo "O", segundo técnica descrita por Furtado e Lourenço Neto (1994).

As amostras de leite cru e pasteurizado foram submetidas às seguintes análises:

Fosfatase alcalina e peroxidase - segundo técnicas descritas por Brasil (1980).

Acidez titulável - pelo método de titulação com hidróxido de sódio N/9 (solução Dornic), em presença de fenolftaleína (solução indicadora), segundo Lanara (1981).

Gordura - pelo método butirométrico de GerberVan Gulik, segundo normas do Lanara (1981).

Densidade - a densidade das amostras foram determinadas pela leitura direta, utilizando um termolactodensímetro segundo Quevenne, corrigindo-se o efeito da temperatura pelo método descrito nas normas analíticas do Instituto Adolfo Lutz (1985).

Extrato seco total (EST) - a determinaçao do EST no leite foi feita pelo método indireto, utilizandose a fórmula de Fleishmann, descrita por Silva (1997).

Crioscopia - a depressão do ponto de congelamento (DPC) das amostras foi determinada por meio de um crioscópio eletrônico ITR (modelo MK 540), em graus Hortvet $\left({ }^{\circ} \mathrm{H}\right)$.

Proteína - o teor de nitrogênio total (NT) das amostras do leite cru e pasteurizado em cada fabricação foi determinado pelo método micrométrico de Kjeldahl
(AOAC, 1995), utilizando-se o fator 6,38 para estimativa do teor de proteína total, de acordo com Kosikowski (1977).

Após coagulação da massa, procedeu-se ao corte da mesma com o auxílio de duas liras, sendo uma vertical e outra horizontal. As amostras de soro no corte foram coletadas cerca de 5-10 minutos após o corte da massa e foram analisadas quanto aos teores de gordura e sólidos totais, densidade e acidez, segundo metodologias descritas anteriormente para o leite.

Nos queijos, foram realizadas as seguintes análises:

$p H$ - determinado com o auxílio de um potenciômetro HANNA (modelo HI 8314) previamente calibrado, efetuando-se quatro leituras por amostra.

Extrato seco total (EST) - pelo método de secagem em estufa a $105^{\circ} \mathrm{C}$ (AOAC, 1995).

Umidade - a determinação da umidade das amostras de queijo foi calculada por diferença (100\% porcentagem de extrato seco total).

Gordura e gordura no extrato seco (GES) - o teor de gordura das amostras de queijo foi determinado pelo método de Van Gulik, utilizando-se centrífuga tipo Gerber da marca FANEM, como descrito por Brasil (1980). Quanto aos teores de gordura no extrato seco (GES), eles foram calculados dividindo-se os teores de gordura do queijo pelo seu teor de EST.

Sal - o teor de sal dos queijos foi determinado pelo teste de Volhard modificado, descrito por Kosikowski (1977).

Sal na umidade (sal/umidade) - os teores de sal na umidade dos queijos foram determinados pela fórmula:

$$
\text { sal/umidade }(\%)=\frac{\text { sal }}{\text { sal }+ \text { umidade }} \times 100
$$

Atividade da água (Aw) - a atividade de água das amostras de queijo foi calculada pela fórmula proposta por Antunes et al. (1992), utilizando-se o valor médio do teor de sal/umidade do queijo.

Cálculo das porcentagens de transição de gordura e sólidos totais do leite para o queijo - Para a determinação das cifras de transição, foram utilizados cálculos matemáticos descritos por Furtado (1973) e Wolfschoon-Pombo (1983). Esses cálculos foram baseados na composição físico-química do leite e soro de cada fabricação, bem como na composição físicoquímica dos queijos obtidos e o seu rendimento em $\mathrm{kg}$.

Cálculo do rendimento de fabricação (litros de leite/kg de queijo) - os cálculos do rendimento de cada 
fabricação foram realizados por meio da divisão do volume de leite empregado no processamento (100 litros) pela soma da massa dos queijos (em $\mathrm{kg}$ ), obtida antes da salga.

Os valores médios de rendimento, transição de sólidos totais e gordura, e composição físico-química do leite, soro e queijo foram submetidos à análise de variância e as comparações entre os tratamentos foram feitas utilizando-se o teste Tukey a 5\% de probabilidade.

\section{RESULTADOS E DISCUSSÃO}

Os valores médios da composição físico-química do leite cru e do pasteurizado, pelos sistemas HTST e injeção direta de vapor, encontram-se na Tabela 1. Para o leite cru e o pasteurizado pelo processo HTST, os dados estão dentro da faixa normal para todos os parâmetros analisados. Entretanto, para o leite pasteurizado pelo sistema de injeção direta de vapor, houve variação significativa de todos os resultados. Como o sistema injeção direta de vapor incorpora água ao leite (cerca de $8,5 \%$, com base no teor de sólidos totais, e 9,4\%, com base na crioscopia do leite antes e após pasteurização), há como conseqüência diluição da acidez e diminuição na concentração dos componentes sólidos, o que leva ao abaixamento da densidade. A elevação do teor de água eleva o ponto de congelamento (DPC), fazendo-o aproximar-se ao da água pura. É importante ressaltar que a incorporação de água ao leite durante a pasteurização não constitui uma prática fraudulenta. Essa prática faz parte do sistema e pode ser considerada uma etapa do processamento, fazendo com que haja aumento significativo no rendimento. Diante disso, o sistema de injeção direta de vapor se torna vantajoso para a produção de queijos.

Os testes de fosfatase alcalina e peroxidase foram realizados para verificar a eficiência da pasteurização do leite, uma vez que as curvas de inativação dessas enzimas encontram-se próximas daquelas da pasteurização, sendo a fosfatase alcalina menos resistente e a peroxidase mais resistente. Dessa forma, o leite pasteurizado deve apresentar atividade da fosfatase alcalina negativa e peroxidase positiva, o que ocorreu nos sistemas utilizados, demonstrando que ambos os leites foram realmente pasteurizados (Tabela 2 ).

$\mathrm{Na}$ fabricação de queijos, é importante conhecer a composição do soro. Sua maior ou menor riqueza fornece boa indicação das perdas acontecidas durante a fabricação, uma vez que os sólidos do leite serão repartidos entre os grãos da coalhada, que irão formar o queijo e o soro. Dessa forma, é importante que o soro seja o mais pobre possível, o que indicaria maior rendimento de fabricação.

TABELA 1 - Valores médios de composição físicoquímica do leite cru e do pasteurizado, pelos sistemas HTST e injeção direta de vapor (IDV).

\begin{tabular}{lccc}
\hline \multicolumn{1}{c}{ Parâmetros } & Cru & HTST & IDV \\
\hline Acidez $\left({ }^{\circ} \mathrm{D}\right)^{1}$ & $16,70 \mathrm{a}$ & $16,70 \mathrm{a}$ & $15,50 \mathrm{~b}$ \\
Gordura $(\%)^{1}$ & $3,50 \mathrm{a}$ & $3,46 \mathrm{a}$ & $3,24 \mathrm{~b}$ \\
Sólidos totais $(\%)^{1}$ & $12,31 \mathrm{a}$ & $12,21 \mathrm{a}$ & $11,26 \mathrm{~b}$ \\
Proteína $(\%)^{1}$ & $3,38 \mathrm{a}$ & $3,37 \mathrm{a}$ & $2,77 \mathrm{~b}$ \\
Crioscopia $\left({ }^{\circ} \mathrm{H}\right)^{1}$ & $-0,538 \mathrm{~b}$ & $-0,538 \mathrm{~b}$ & $-0,492 \mathrm{a}$ \\
Densidade $(\mathrm{g} / \mathrm{ml})^{1}$ & $1,032 \mathrm{a}$ & $1,031 \mathrm{a}$ & $1,028 \mathrm{~b}$ \\
\hline
\end{tabular}

${ }^{1}$ Médias seguidas da mesma letra na linha não diferem estatisticamente pelo teste Tukey, a $5 \%$ de probabilidade. Valores médios obtidos em seis observações ou fabricações.

TABELA 2 - Testes de fosfatase alcalina e peroxidase no leite cru e pasteurizado pelos sistemas HTST e injeção direta de vapor (IDV).

\begin{tabular}{lccc}
\hline \multicolumn{1}{c}{ Teste } & Cru & HTST & IDV \\
\hline Fosfatase alcalina & + & - & - \\
Peroxidase & + & + & + \\
\hline
\end{tabular}

O sistema de injeção direta de vapor incorpora água ao leite. Esse excesso de água sai no soro durante a fabricação, aumentando seu volume e, conseqüentemente, diluindo seus constituintes sólidos.

Pode ser observado que o leite pasteurizado por injeção direta de vapor produziu soro com menor teor de gordura (Tabela 3). Dois aspectos devem ser considerados: o primeiro é que ocorre nesse sistema maior produção de soro, advinda da água incorporada ao leite, e o segundo é maior retenção de gordura nos grãos. Essa maior retenção de gordura no interior dos grãos ocorre em função da ligeira homogeneização do leite no sistema por injeção direta de vapor. Essa ligeira homogeneização melhora a retenção de gordura no interior dos grãos, podendo aumentar o teor de gordura do queijo. 
TABELA 3 - Valores médios de composição físicoquímica do soro do queijo prato produzido pelos sistemas HTST e injeção direta de vapor (IDV).

\begin{tabular}{lcc}
\hline \multirow{2}{*}{ Parâmetros } & \multicolumn{2}{c}{ Soro Corte $^{1}$} \\
\cline { 2 - 3 } & HTST & IDV \\
\hline Acidez $\left({ }^{\circ} \mathrm{D}\right)$ & $12,00 \mathrm{a}$ & $10,00 \mathrm{~b}$ \\
Gordura $(\%)$ & $0,73 \mathrm{a}$ & $0,50 \mathrm{~b}$ \\
Sólidos totais $(\%)$ & $7,35 \mathrm{a}$ & $7,10 \mathrm{~b}$ \\
Sólidos desengordurados $(\%)$ & $6,62 \mathrm{a}$ & $6,60 \mathrm{a}$ \\
Densidade $(\mathrm{g} / \mathrm{ml})$ & $1,025 \mathrm{a}$ & $1,025 \mathrm{a}$ \\
\hline
\end{tabular}

no rendimento de queijos. A introdução direta de vapor no leite, visando ao seu aquecimento, provoca redução no tamanho dos glóbulos de gordura (SBAMPATO, 1996), além de provocar uma "homogeneização" do leite, o que facilita a retenção da gordura na coalhada. Assim, o queijo resultante desse processo normalmente apresenta elevado teor de gordura e características de textura próprias.

TABELA 4 - Valores médios de rendimento e transição de sólidos totais e gordura do leite pasteurizado pelos sistemas HTST e injeção direta de vapor (IDV), na fabricação do queijo prato.

\begin{tabular}{lcc}
\hline \multicolumn{1}{c}{ Parâmetros } & HTST & IDV \\
\hline Rendimento (1 de leite/kg de queijo) $^{1}$ & $9,54 \mathrm{a}$ & $8,48 \mathrm{~b}$ \\
\% de transição de gordura $^{1}$ & $80,91 \mathrm{~b}$ & $86,30 \mathrm{a}$ \\
\% de transição de sólidos totais $^{1}$ & $45,62 \mathrm{a}$ & $44,05 \mathrm{a}$ \\
\hline
\end{tabular}

Observa-se ainda a ocorrência da diminuição da acidez e diluição dos sólidos totais no soro proveniente do sistema injeção direta de vapor, em razão da menor diluição do teor de gordura. Os sólidos desengordurados não apresentaram diferença $(\mathrm{P}>0,05)$ entre os tratamentos, provavelmente devido ao maior carreamento de sólidos solúveis pelo excesso de água, o que provocou a manutenção da densidade.

Os valores médios de rendimento e de transição de sólidos totais e gordura nos processos de fabricação que utilizaram leite pasteurizado pelos sistemas HTST e injeção direta de vapor estão apresentados na Tabela 4. Observa-se rendimento superior $(\mathrm{P}<0,05)$ nos queijos fabricados com leite pasteurizado pelo sistema de injeção direta de vapor (IDV), comparado com o HTST. O maior rendimento observado está relacionado com o maior aproveitamento dos constituintes do leite no sistema injeção direta de vapor, principalmente a gordura, uma vez que sua transição foi 5,39 pontos percentuais maior que no HTST. Como conseqüência, por esse sistema produzem-se queijos com maior teor de gordura total e gordura no extrato seco, conforme observa-se na Tabela 5.

Ventura et al. (1984) e Sbampato (1996), trabalhando com queijo gorgonzola e prato, respectivamente, encontraram maior rendimento do queijo produzido com leite pasteurizado pelo sistema ejetor de vapor, comparado ao sistema HTST. Os sistemas ejetor de vapor e injeção direta de vapor, apesar de apresentarem algumas particularidades, apresentam efeitos idênticos
Na Tabela 5 estão apresentados os valores médios de alguns parâmetros físico-químicos dos queijos fabricados com leites pasteurizados pelos dois sistemas. Observam-se aumento $(\mathrm{P}<0,05)$ nos teores de gordura, gordura no extrato seco do queijo e tendência de maior umidade (embora estatisticamente não significativa) quando se utilizou o sistema de injeção direta de vapor para pasteurização do leite. $\mathrm{O}$ aumento desses constituintes no leite foi responsável pelo aumento da conversão de leite para queijo durante o processo de fabricação (Tabela 4), principalmente em função da maior retenção de gordura, o que levou também à maior concentração de gordura no extrato seco. A maior umidade e concentração de gordura provocam maior maciez da massa do queijo, o que foi empiricamente observado. Entretanto, deve-se considerar que esses dois fatores levam à diminuição do período de validade do produto.

O teor de sal, embora não tenha apresentando diferença significativa, apresentou valor mais elevado (14\% a mais) no queijo produzido pelo sistema injeção direta de vapor, quando comparado com o produzido pelo HTST (Tabela 5). Isso ocorreu devido à maior umidade obtida naquele sistema, proporcionando também maior difusão de sal na massa dos queijos mais

\section{${ }^{1}$ Médias seguidas da mesma letra na linha não diferem estatisticamente pelo teste Tukey a $5 \%$ de probabilida- de. Valores médios obtidos de seis repetições.}


úmidos. Observa-se que o teor de sal na umidade foi também maior no mesmo sistema, o que levou à ligeira redução da atividade de água desses queijos, embora não tenha apresentado diferença estatística $(\mathrm{P}>0,05)$.

TABELA 5 - Valores médios de composição físicoquímica do queijo prato com um dia de maturação, produzido com leite pasteurizado pelos sistemas HTST e injeção direta de vapor (IDV).

\begin{tabular}{lrr}
\hline \multicolumn{1}{c}{ Parâmetros } & HTST & \multicolumn{1}{c}{ IDV } \\
\hline $\mathrm{pH}^{1}$ & $4,92 \mathrm{a}$ & $5,03 \mathrm{a}$ \\
Umidade $(\%)^{1}$ & $45,80 \mathrm{a}$ & $47,38 \mathrm{a}$ \\
Sal $(\%)^{1}$ & $1,71 \mathrm{a}$ & $1,95 \mathrm{a}$ \\
Gordura $(\%)^{1}$ & $27,02 \mathrm{~b}$ & $29,06 \mathrm{a}$ \\
GES (\%) & $49,88 \mathrm{~b}$ & $55,24 \mathrm{a}$ \\
Sólidos totais $(\%)^{1}$ & $54,20 \mathrm{a}$ & $52,62 \mathrm{a}$ \\
Sal na umidade $(\%)^{1}$ & $3,60 \mathrm{a}$ & $3,95 \mathrm{a}$ \\
Atividade da água $^{1}$ & $0,977 \mathrm{a}$ & $0,973 \mathrm{a}$ \\
\hline
\end{tabular}

${ }^{1}$ Médias seguidas da mesma letra na linha não diferem estatisticamente pelo teste Tukey, a $5 \%$ de probabilidade. Valores médios obtidos de seis repetições.

\section{CONCLUSÕES}

A utilização do sistema injeção direta de vapor na pasteurização do leite para a elaboração do queijo prato resultou em maior rendimento de fabricação (litros de leite/kg de queijo). Isso ocorre porque esse sistema permite melhor aproveitamento da gordura, quando comparando com o sistema HTST.

O sistema de pasteurização de injeção direta de vapor proporcionou menor acidez inicial no queijo, além de proporcionar queijos com maior teor de gordura.

\section{REFERÊNCIAS BIBLIOGRÁFICAS}

ANTUNES, L. A. F.; TEIXEIRA, E. C.; SILVA, R. S. S. F. Models for determination of water activity in Prato cheese. Journal Dairy Science, Champain, v. 75, n. 1, p. 104-109, Jan. 1992.
ASSOCIATION OF OFFICIAL ANALYTICAL CHEMISTS. Official methods of analysis. 12. ed. Washington, 1995. $1094 \mathrm{p}$.

BRASIL. Ministério da Agricultura. Regulamento da inspeção industrial e sanitária de produtos de origem animal - RIISPOA. Brasília, 1980. 116 p.

FLEISCHMANN, W. Tratado de Lecheria. Barcelona: Gustavo Gili, 1924. 240 p.

FOLEGATTI, M. L. S. Avaliação do uso de quimosina produzida por Aspergillus niger (var. awamori) na fabricação do queijo tipo Prato. 1994. 65 f. Dissertação (Mestrado em Ciências Alimentos) - Universidade Estadual de Campinas, Campinas, 1994.

FURTADO, M. M. Tecnologia de fabricação de queijos. 3. ed. Juiz de Fora: EPAMIG/ILCT, 1973. 215 p.

FURTADO, M. M.; LOURENÇO NETO, J. P. M. Tecnologia de queijos: manual técnico para produção industrial de queijos. São Paulo: Dipemar, 1994. 118 p.

HASHZUME, K.; SATO, T. Gel-forming characteristic of milk proteins. 1: effects of heat treatment. Journal of Dairy Science, Champain, v. 71, n. 12, p. 14391446, Dec. 1988.

INSTITUTO ADOLFO LUTZ. Normas analíticas do Instituto Adolfo Lutz: métodos químicos e físicos para análise de alimentos. 3. ed. São Paulo, 1985. v. 1, 533 p.

KOSIKOWSKY, F. Cheese and fermented milk foods. 2. ed. Ann Arbor: Edwards, 1977. 711 p.

LABORATÓRIO NACIONAL DE REFERÊNCIA ANIMAL - LANARA. Métodos analíticos oficiais para controle de produtos de origem animal e seus ingredientes. II: métodos físicos e químicos. Brasília, 1981. 85 p.

MARZIALI, A. S.; NG-KWA-HANG, K. F. Effects of milk composition and genetic polymorphism on cheese composition. Journal of Dairy Science, Champaign, v. 69, n. 10, p. 25333-25420, Oct. 1986.

SAN JOSÉ, C. Efectos de la temperatura sobre la Ieche y sus componentes. Revista Espanôla de Lecheria, Madrid, v. 34, n. 114, p. 193-211, sept./oct. 1979. 
SBAMPATO, C. G. Propriedades lipolíticas e sensoriais do queijo tipo gorgonzola elaborado com leite pasteurizado pelos sistemas HTST e ejetor de vapor. 1996. 69 f. Dissertação (Mestrado em Ciência dos Alimentos) - Universidade Federal de Lavras, Lavras, 1996.

SECRETARIA DA AGRICULTURA E DO ABASTECIMENTO DO PARANÁ. Origem e informação sobre queijos. Leite e Derivados, Curitiba, v. 4, n. 6, p. 80-88, jun. 1992.

SILVA, J. O. Efeito do calor sobre o leite. Revista do Instituto de Laticínios Cândido Tostes, Juiz de Fora, v. 30, n. 30, p. 61-67, 1975.

SILVA, P. H. F. da. Físico-química do leite e derivados. Juiz de Fora: Oficina de Impressão Gráfica, 1997. $190 \mathrm{p}$.

SOUZA, E. A. Tecnologia da fabricação de queijos. Juiz de Fora: Ed. Lar Católico, 1960. 116 p.
VENTURA, R. F. Caracterização do sistema ejetor de vapor na pasteurização de leite destinado à fabricação de queijos. 1981. 144 f. Dissertação (Mestrado em Ciência dos Alimentos) - Universidade Estadual de Campinas, Campinas, 1981.

VENTURA, R. F.; FURTADO, M. M.; WOLFSCHOON-POMBO, A. F.; LOURENÇO NETO, J. P. M.; LIMA, A. Queijo prato: comparação de fabricação usando leite pasteurizado por sistema de placas e ejetor de vapor: nota prévia. Revista do Instituto de Laticínios Cândido Tostes, Juiz de Fora, v. 39, n. 235, p. 59-70, set./out. 1984.

VENTURA, R. F.; RUSIG, O. Ejetor de vapor: sistema de pasteurização de leite destinado à fabricação de queijos: $7^{\mathrm{a}}$ parte. Revista de Laticínios Cândido Tostes, Juiz de Fora, v. 38, n. 227, p. 3-16, jul./ago. 1983.

WOLFSCHOON-POMBO, A. F. Índices de proteólise em alguns queijos brasileiros. Boletim do Leite, Rio de Janeiro, v. 51, n. 661, p. 1-8, nov. 1983. 